\title{
Permanências e Descontinuidades nas Concepções Contemporâneas de Casamento na Perspectiva de Casais Longevos
}

\author{
Fabio Scorsolini-Comin ${ }^{1, *}$, Júnia Denise Alves-Silva ${ }^{2}, \&$ Manoel Antônio dos Santos ${ }^{1}$ \\ ${ }^{1}$ Universidade de São Paulo, São Paulo, SP, Brasil \\ ${ }^{2}$ Universidade Federal do Triângulo Mineiro, Uberaba, MG, Brasil
}

\begin{abstract}
RESUMO - O objetivo deste estudo foi compreender os movimentos de permanências e descontinuidades nas concepções contemporâneas de casamento, a partir da perspectiva de casais longevos, ou seja, unidos há mais de 30 anos. Foram entrevistados sete casais com média de idade de 68,9 anos e unidos há 45,7 anos, em média. Aplicou-se uma entrevista semiestruturada em cada casal (díade). Os resultados mostraram que o respeito à liberdade de se casar e divorciar parece ser a inovação que mais repercutiu nos casais entrevistados. Os participantes tiveram que reestruturar suas concepções sobre o casamento para poderem lidar com as novas possibilidades que emergem na atualidade. As mudanças percebidas se referem mais aos comportamentos dos cônjuges na contemporaneidade e não à estrutura da instituição casamento, vista como estável e confiável.
\end{abstract}

PALAVRAS-CHAVE: casamento, relações conjugais, dinâmica de casal

\section{Continuities and Discontinuities in Contemporary Conceptions of Marriage from the Perspective of Long-Term Couples}

\begin{abstract}
This study aimed to understand the movements of continuities and discontinuities in contemporary conceptions of marriage from the perspective of couples in long term marriages, that is, those that last longer than 30 years. Seven couples (mean age $=68.9$ years) who were married for 45.7 years on average. Semi-structured interviews with each couple were carried out (dyad). The results showed that respect for freedom to marry and divorce seems to be the innovation that most affected the interviewed couples. Participants had to restructure their marriage conceptions in order to deal with the new possibilities that emerge nowadays. Perceived changes are associated with the behavior of couples in contemporary days and not to the structure of marriage as institution, seen as stable and reliable.
\end{abstract}

KEYWORDS: marriage, marital relations, couple dynamics

O conceito de família tem evoluído ao longo da história. De acordo com Ariès (1981), a família antiga não tinha como base uma função afetiva. Ela surgia, primeiramente, a fim de que os bens fossem conservados e a honra dos familiares protegida. Na contemporaneidade, a afetividade é incorporada à definição de família, promovendo a emergência de noções que a consideram um espaço privilegiado que permite a socialização entre as pessoas e propicia a prática da tolerância, convivência e divisão de responsabilidades. A organização familiar possibilita também o exercício da cidadania, o desenvolvimento dos laços afetivos e do bem-estar dos seus componentes, independentemente do arranjo familiar. Essas características constituem a família como a primeira instituição com valores culturais e normas sociais com a qual a pessoa mantém contato em sua vida, como abordado na literatura científica (Féres-Carneiro \& Diniz Neto, 2010).

No que se refere às concepções sobre o casamento no contexto brasileiro, durante o século XIX, as uniões eram marcadas pelo interesse de pais ambiciosos em "casar bem" seus filhos. As celebrações se davam a partir de razões econômicas, interesses sociais e preconceitos raciais, sem considerar a opinião e o desejo dos cônjuges (Costa, 1983). A fase do namoro quase nunca existia e o noivado era breve. $\mathrm{Na}$ transição do século XIX para o XX, deu-se início à propagação de uma noção de casamento não vinculado

*E-mail: fabioscorsolini@gmail.com 
apenas à satisfação nos negócios e na transmissão dos bens materiais, com menos influência da família e da religião (Del Priore, 2006). A expansão do capitalismo gerou desenvolvimento e modernização, o que culminou com a mudança dos hábitos e costumes, assim como dos padrões das relações interpessoais. Os casamentos por conveniência foram gradativamente substituídos por uniões pautadas no envolvimento afetivo, não sendo mais vistos apenas sob uma aura romântica, mas também como um sentimento recíproco que solidificaria o vínculo conjugal. No entanto, o casamento deve ser compreendido também como uma instituição sociossexual, por meio da qual se opera uma regulação da sexualidade, sendo ao mesmo tempo um veículo de integração social e de divisão social (Therborn, 2006).

O que se observa, atualmente, é uma ressignificação da instituição familiar e da própria noção de casamento. Não há mais um padrão definido ou um modelo único que se impõe, pois a família atual se apresenta em configurações diversas, predominando a pluralidade em detrimento de um modelo nuclear, legado da sociedade patriarcal (Vaitsman, 1994). Vivencia-se também o fenômeno do aumento do número de famílias monoparentais no país, principalmente daquelas em que a mulher assume o papel de chefe do grupo familiar. Essa mudança teve início durante a década de 1980, quando a tradição do casamento transformou-se significativamente, em um processo em que ele deixou de ser visto como o ideal de vida para todas as mulheres. Na mesma época, ampliou-se a participação feminina no mercado de trabalho, impulsionada pela crise econômica que atingiu fortemente as famílias. Em termos demográficos, entre as mudanças mais significativas ocorridas na família, notadamente no contexto brasileiro, destacam-se a ampliação do número de divórcios e separações, a redução do tamanho dos grupos familiares e a queda das taxas de fecundidade, além do adiamento da maternidade/ paternidade (Ribeiro, Sabóia, Branco, \& Bregman, 2010).

De acordo com dados do Instituto Brasileiro de Geografia e Estatística (IBGE, 2015), entre os anos de 2004 e 2014, o número de divórcios no Brasil aumentou 161,4\%. De 1984 a 2014, houve redução na duração dos casamentos, ou seja, as uniões passaram a durar menos, em média 15 anos. A partir desses dados, a manutenção do casamento tem emergido como uma temática de interesse no campo dos estudos sobre família e na clínica de casal (Scorsolini-Comin, 2014). Para além das ponderações de que os casamentos estão cada vez durando menos, há a necessidade de promover uma revisão crítica acerca do que se compreende como laço conjugal, tendo em vista as transformações psicológicas, sociais, econômicas, políticas e culturais das últimas décadas. A durabilidade de um relacionamento afetivo pode estar condicionada tanto ao período histórico-cultural em que se vive quanto ao efetivo trabalho dos cônjuges, no sentido de desenvolver estratégias cada vez mais adequadas para a manutenção de relações satisfatórias, como destacado na literatura científica (Rosowsky, King, Coolidge, Rhoades, \& Segal, 2012).

Tendo como norte a durabilidade do casamento e a sua perpetuação ao longo dos anos, os denominados casamentos de longa duração, ou seja, casais unidos há mais de 20 anos, passaram a despertar o interesse dos pesquisadores da área de conjugalidade (Sharlin, Kaslow, \& Hammerschmidt, 2000). Tais estudos foram desenvolvidos com recortes específicos, como a questão da satisfação conjugal (Bachand $\&$ Caron, 2001; Norgren, Souza, Kaslow, Hammerschmidt, \& Sharlin, 2004), do coping (Landis, Peter-Wight, Martin, \& Bodenmann, 2013), do cuidado em saúde (Sandberg, Miller, Harper, Robila, \& Davey, 2009), do papel da parentalidade (Grizólio, Scorsolini-Comin, \& Santos, 2015) e das estratégias de resolução de conflitos desenvolvidas nesses relacionamentos longevos (Ahmadi, Rezazade, Saadat, Kimiaei, \& Zade, 2015; Costa, Mosmann, \& Falcke, 2015). No entanto, algumas dessas investigações privilegiam determinadas descrições do que seja o casamento, aliando-o a uma noção que nem sempre considera os movimentos de mudança e permanência ao longo do tempo, inclusive no relato das motivações para a manutenção do casamento (Scorsolini-Comin, 2014). No contexto nacional, há uma quantidade exígua de trabalhos científicos que possibilitam uma compreensão mais ampla a respeito dessa temática (Costa \& Mosmann, 2015; Silva, Scorsolini-Comin, \& Santos, 2018), com pouco destaque para as transformações que ocorrem na chamada conjugalidade de longa duração (Campos, Scorsolini-Comin, \& Santos, 2017; Margelisch, Schneewind, Violette, \& Perrig-Chiello, 2015).

A partir desse panorama, o objetivo deste estudo foi compreender os movimentos de permanências e descontinuidades nas concepções contemporâneas de casamento, a partir da perspectiva de casais longevos. Busca-se apreender as concepções sobre casamento ao longo dos anos, tendo como norte tanto as transformações socioculturais que incidiram sobre essa instituição, como as reflexões de cônjuges engajados em relacionamentos que atravessaram um período de mais de três décadas.

\section{MÉTODO}

\section{Tipo de Estudo}

Trata-se de um estudo de caráter exploratório, de corte transversal, apoiado na abordagem qualitativa de pesquisa.
O recorte proposto neste estudo é parte de uma investigação mais ampla, que teve como objetivo compreender os processos de transformação da conjugalidade em casamentos de longa duração. 


\section{Participantes}

Participaram do presente estudo sete casais heterossexuais em primeiras núpcias, com idade média de 68,9 anos, sendo 70,1 para homens e 67,7 para mulheres, residentes em uma cidade de médio porte do interior do Estado de Minas Gerais. A escolaridade predominante foi o Ensino Fundamental incompleto (seis participantes), e a maioria dos participantes se declarou católica. O tempo médio de casamento foi de 45,7 anos (ou seja, são casais que se uniram antes da década de 1980), com média de 3,4 filhos por casal. Esses casais coabitavam desde o início do casamento e nunca haviam se separado ao longo desses anos de convívio conjugal.

\section{Instrumento}

Foi empregado um roteiro de entrevista semiestruturado, respondido em conjunto por cada casal, contendo perguntas sobre a conjugalidade ao longo do tempo, contemplando desde o início do namoro, a transição para o casamento e a transição para a parentalidade, bem como as experiências conjugais vivenciadas ao longo do tempo e seus movimentos de mudanças. Priorizou-se, ao longo da entrevista, a situação de interação dos cônjuges e o relato das mudanças ocorridas nas concepções vigentes de casamento na época em que se casaram e no momento atual.

\section{Procedimento}

Coleta de Dados. Os participantes foram recrutados a partir de contatos realizados em uma cidade de médio porte do Estado de Minas Gerais, por meio de indicações da rede social dos pesquisadores e, posteriormente, pela técnica da bola de neve. Após este contato, os pesquisadores apresentaram o projeto e explicaram os termos da participação voluntária no estudo. Os participantes leram o Termo de Consentimento Livre e Esclarecido e, por consentirem, assinaram o documento, o que deflagrou o início da coleta de dados. As entrevistas com os casais foram realizadas em suas próprias residências. As perguntas eram apresentadas às díades e, sempre que necessário, a entrevistadora buscava fomentar que ambos respondessem ou interagissem para responder aos questionamentos.

Análise dos Dados. As entrevistas com os casais foram transcritas na íntegra e literalmente para posterior análise. Foi realizada uma análise de conteúdo temática (Triviños, 1987), a fim de compreender as principais mudanças e permanências na concepção de casamento a partir das falas dos entrevistados. A partir da recorrência de conteúdos nas falas dos cônjuges entrevistados, foram construídas, a posteriori, as seguintes categorias: (a) $\mathrm{O}$ casamento de "antigamente": exigências em relação à mulher e rigidez de papéis; (b) Permanências; (c) O casamento "de hoje": flexibilização dos papéis de gênero; e (d) A (im) possibilidade do divórcio.

A discussão dos resultados, sistematizados nas categorias de análise, ocorreu com base na literatura científica no campo da família e conjugalidade (Costa, 1983; Borges, 2013; Gallagher, Féres-Carneiro, \& Henriques, 2013; Sarti, 2010; Scorsolini-Comin \& Santos, 2012; Therborn, 2006), juntamente com as produções científicas acerca dos casamentos de longa duração (Ahmadi, Rezazade, Saadat, Kimiaei, \& Zade, 2015; Bachand \& Caron, 2001; Grizólio, Scorsolini-Comin, \& Santos, 2015; Landis, Peter-Wight, Martin, \& Bodenmann, 2013; Margelisch, Schneewind, Violette, \& Perrig-Chiello, 2015; Norgren et al., 2004).

\section{Disposições Éticas}

O projeto que deu origem ao estudo foi aprovado pelo Comitê de Ética em Pesquisa da Universidade Federal do Triângulo Mineiro (Protocolo CEP 2011/1936).

\section{RESULTADOS E DISCUSSÃO}

\section{O Casamento de “Antigamente": Exigências em relação à Mulher e Rigidez de Papéis}

O casamento de "antigamente", no contexto dos participantes deste estudo, refere-se aos relacionamentos amorosos que se iniciaram entre as décadas de 1950 e 1980 , ou seja, diz respeito aos casais que se uniram entre 30 e 60 anos atrás e que, portanto, provavelmente passaram por diferentes transformações ao longo dos anos, juntamente com as redefinições que incidiram sobre as concepções do que é ser casal e família na contemporaneidade. Nesta categoria temática, estão incorporadas as falas relativas ao que se considera como pré-requisitos para um bom casamento à época em que os cônjuges se conheceram, ou seja, antes da década de 1980. Foram incluídas as compreensões sobre as condições necessárias para que homens e mulheres pudessem se casar. Neste aspecto, houve uma dissonância em termos de gênero, haja vista que foram salientadas as características, sobretudo femininas, o que revela uma percepção da condição da mulher como pivô central do casal, e também como principal esteio responsável pela manutenção do enlace conjugal ao longo do tempo.

A gente casou numa época, e eu tô vendo esses dias com as meninas também, que tinha que saber fazer tudo pra poder... Tinha que saber cozinhar. Hoje não, hoje as mulher num ajuda, 
num cozinha, num lava, num passa, num faz nada. Então, ai eu acho que também poderia tá fazendo uma bagunça. (Esposa 1, 59 anos, casada há 33 anos).

Era muito importante, principalmente, da moça casar virgem. [...] É, num podia, é, se juntar, falar: "Fulano juntou, num casou". Aquilo era um assunto que demorava pro povo esquecer, despreocupar daquilo. (Esposo 3, 66 anos, casado há 42 anos).

É, era assim igual ele falou, pros pais assim, né, era um, como se diz, um orgulho, uma honra casar uma filha bem casada, naquela época tinha que casar bem casada, né. (Esposa 3, 61 anos, casada há 42 anos)

A virgindade emergiu como uma condição necessária à mulher, que a habilitava ao casamento, um pré-requisito para os pais da noiva realizarem o ideal de terem "uma filha bem casada". A suposição de virgindade evidenciava, perante a coletividade, que ela havia tido uma vida pregressa regrada e devotada à família e aos afazeres domésticos, sendo, portanto, digna de se casar e ter filhos. A ausência de experiência sexual da mulher era uma condição apreciada socialmente, o que se desfazia caso a moça não formalizasse a união e decidisse apenas "morar" com o companheiro. Se não se casasse oficialmente, seria "mal vista" pela sociedade, inclusive porque deixaria de ostentar a condição virginal para que pudesse, no futuro, se casar. A união valorizada era, portanto, o casamento, não sendo considerados arranjos que divergissem do matrimônio. Ter a filha bem casada significava que o matrimônio havia ocorrido dentro dos parâmetros aceitos à época, ou seja, uma mulher virgem, com dotes domésticos adquiridos mediante o treino de habilidades transmitidas pela família de origem, unida a um homem trabalhador e honesto. Tratava-se de uma mulher disciplinada a exercer múltiplas funções no espaço privado, que pudesse ser dona de casa, cuidar dos filhos e do esposo, reservando ao homem o papel de chefe da família, ou seja, de uma organização mais ampla do que a doméstica, que seria o domínio do espaço público, conforme explorado no estudo de Sarti (2010).

Nas entrevistas realizadas, houve poucos relatos sobre a necessidade de se ter um vínculo amoroso entre os parceiros, predominando a concepção de um relacionamento que deveria ser habilmente construído no cotidiano, por meio da reprodução automática de papéis e funções prescritas, para ser socialmente aceito. Em relação ao homem, as exigências eram menores, bastando que o mesmo fosse (ou aparentasse ser) honesto, proveniente de uma boa família e que, por meio de seu trabalho, mostrasse ser competente para amealhar os recursos necessários para prover a nova família e reafirmar sua masculinidade (Sarti, 2010). Sua virgindade sequer era mencionada, sendo implicitamente desejável que tivesse mais experiência prévia do que a mulher, tanto em termos de namoros como na prática sexual. Percebe-se, portanto, uma disparidade na construção de gênero em relação ao que se permitia ao homem e à mulher no contexto da conjugalidade. Também a questão da virgindade retomava a concepção do casamento como entidade sociossexual destinada a conter e regular a sexualidade. O controle social da virgindade feminina só poderia ser diminuído quando a mulher se casasse e, assim, pudesse se sentir autorizada a expressar sua sexualidade, dentro dos limites do pudor, do recato e da decência, ou seja, de modo comedido e com vistas à procriação (Therborn, 2006).

Os entrevistados, em sua maioria, trouxeram relatos sobre como era o casamento à época em que se uniram. Destacaram determinados valores que eram mais "praticados", assim como certas características que deveriam estar presentes no relacionamento para que o vínculo fosse socialmente aceito $\mathrm{e}$ respeitado. As responsabilidades e funções eram fortemente marcadas pelo gênero: a mulher deveria cuidar da casa, zelar pelo bem-estar do marido e dos filhos; o homem, por sua vez, deveria manter a casa e proteger os demais membros da família, responsabilizando-se por prover materialmente o lar. O compromisso assumido por ocasião do casamento não se referia apenas ao cônjuge, mas se afirmava diante das duas famílias de origem, de modo que a noção de responsabilidade era uma questão que atravessava o casal e, ao mesmo tempo, o constituía.

A responsabilidade. Era muita responsabilidade. Por exemplo, o... A moça, né, ela tinha que assumir a casa, saber fazer alguma coisa. Se num fizesse, tinha que aprender na marra. Erra num dia pra poder fazer no outro dia melhor, pedindo as receitas pra sogra, pra mãe e assumir mesmo, igual eu te falei, assumir o casamento. E... Acho que o rapaz era isso também, a responsabilidade de cuidar duma moça, né, que os pais recomendavam. (Esposa 7, 71 anos, casada há 51 anos)

Era muita pressão dos pais, né. "Oh, você está namorando, mas você tem a responsabilidade”. Dela também deve ser a mesma coisa, os pais já falavam, uma moça num vai, é, como é que cê vai fazer de tirar uma moça de dentro de casa? Então é a pressão, a gente tinha que namorar certinho e noivar $e$ casar. (Esposo 7, 75 anos, casado há 51 anos)

Essa responsabilidade para com a família de origem emergiu de modo associado à (im)possibilidade de se divorciar (o que será aprofundado na quarta categoria analítica), ou, em outras palavras, ao estigma imposto às pessoas que se separavam, notadamente às mulheres. Esse aspecto apareceu em várias passagens recuperadas das entrevistas.

Talvez não fosse como hoje, né? Porque hoje separa-se por qualquer coisa. Naquele tempo, não. Separava, mas quando o motivo era um motivo realmente que, né, chegava. Acho que, quando esgotavam todas as possibilidades, a última era a separação. Hoje não, hoje a primeira opção é a separação, não esgota nenhuma possibilidade. (Esposo 2, 57 anos, casado há 33 anos) 
Naquele tempo era muito reparado um casal largar, separar. Ih... Todo mundo, a familia ficava tudo contrariado e era muito, muito ruim naquele tempo. Tanto que quase num tinha separação naquela época, naquele tempo. (Esposo 4, 86 anos, casado há 66 anos)

Era, tinha preconceito, né. Aí, tanto é que a mulher, quantas vezes a gente ouvia, né: "Nossa, fulana já separou do marido? Nossa, já tá indo nas festas? Ixe!”. (Esposa 6, 58 anos, casada há 32 anos)

Em uma sociedade considerada tradicional, organizada sob rígidas prescrições morais e baseada na cristalização dos papéis de gênero, a ruptura dessa estrutura normalizadora era percebida como perigosa para as futuras gerações e para a continuidade do próprio contexto social. Quando ocorria uma separação, revelava-se também a possibilidade de romper-se o contrato conjugal e, assim, subverter a ordem que imperava (Jablonski, 1998). O preconceito em relação à mulher "desquitada" (ou, a partir da década de 1970, divorciada) era implacável. Nada poderia ser mais desonroso para a mulher do que ser reconhecida nos círculos sociais como uma senhora que fora "largada pelo marido". Isso obviamente não se aplicava ao homem separado, como pode ser observado no excerto de fala a seguir. Este relato reforçou a ideia de que a construção e manutenção da conjugalidade estavam fortemente associadas à figura da mulher, vista como a responsável pelo bom funcionamento do universo doméstico, pelo cuidado da prole e pela preservação da estabilidade do casal, elementos constitutivos dos alicerces da família. Logo, qualquer subversão desses papéis - ou frustração das expectativas de concretização das funções que lhe são vinculadas - era considerada de responsabilidade exclusiva da mulher.

Pro homem era mais fácil. Na cabeça da sociedade, a mulher é que sempre errava. Se ele arrumou outra é porque ela é que fez por onde. Num era boa dona de casa, num era boa mãe, num era boa esposa. Num sabia fazer nada, num dava conta de nada, né. Era vista assim, a mulher como mulher era vista como a senhora das prendas domésticas, né, porque a mulher antigamente era preparada pra quê? Pra casar, né, cozinhar, lavar, passar, aprender a bordar, aprender a costurar e ser mãe. (Esposa 6, 58 anos, casada há 32 anos)

Essas falas veiculam concepções que cristalizam os papéis generificados, diferenciados sob o manto do casamento heterossexual, de modo a reforçar o binarismo de gênero em relação ao que podia ou que era considerado apropriado para homens e mulheres, e também como forma de reafirmar a autoridade masculina (Sarti, 2010). Os pais da noiva delegavam ao futuro marido a tarefa de cuidar e protegê-la, já que a mulher era vista como o "sexo frágil", o que na prática significava continuar a tutelá-la na vida social e familiar. Essa rigidez reforçava o sentido único de família heterossexual, tradicional e burguesa, ainda sem muito espaço para a presença da mulher no mercado de trabalho e dos casais de dupla carreira (Perlin \& Diniz, 2005; Féres-Carneiro \& Diniz Neto, 2010; Garcia \& Tassara, 2001), embora também tenha sido encontrado nos relatos que algumas mulheres passaram a trabalhar após o casamento, pressionadas por necessidades financeiras.

\section{Permanências}

Nesta categoria temática, dá-se destaque para as falas que afirmaram que muito pouco se modificou no conceito de casamento ao longo dos anos. Os cônjuges revelaram que, apesar das diversas mudanças sociais, econômicas e culturais, os motivos que fazem com que as pessoas se unam ainda permanecem intactos, de modo que a instituição casamento mantenha-se essencialmente a mesma, conservando o mesmo sentido e função de outrora, ainda que sobre ela incida certa renovação. $\mathrm{Ou}$ seja, os comportamentos na atualidade são considerados diferentes, mas a visão de matrimônio parece experimentar certa estabilidade, na opinião de alguns entrevistados, como destacado a seguir:

Olha, eu acredito que não mudou muita coisa assim, em termos de visão de matrimônio daquela época pra agora. Eu acredito que a visão ainda é a mesma, né? Apesar das pessoas estão... Estar... Estão, são mais intolerantes, mas ainda a visão... por isso há tantos casamentos, né? O povo ainda continua casando muito ainda. Eu acredito que o pessoal ainda acredita que o casamento é possivel. E a partir do momento que você casa, eu acho que ninguém casa pra se separar, né? Eu acredito que todo mundo casa porque quer, porque ama, porque quer viver uma vida junto. (Esposa 2, 57 anos, casada há 33 anos)

Casamento, na verdade, no meu ponto de vista particular, eu acho que ele sempre foi a mesma coisa, o que muda é o povo, éo comportamento. [...] Mas o casamento, ele sempre foi a mesma coisa, sempre existiu separação, sempre existiu casamentos longos, sempre existiu briga em casamento. Sempre foi a mesma coisa, acho que o que mudou foi o comportamento do povo. (Esposo 2, 57 anos, casado há 33 anos)

O negócio é o seguinte: casal hoje, eles mudam, mas só muda de endereço. Problema é a mesma coisa. A mulher muda, os problemas são a mesma coisa, só muda de endereço. Eu acho que é isso. (Esposo 7, 75 anos, casado há 51 anos)

Embora as mudanças possam ser assinaladas, esses participantes destacaram que o casamento ainda é um fenômeno atual e uma aliança que tem sido intensamente buscada pelas pessoas, o que é corroborado pelas altas taxas de nupcialidade no Brasil (IBGE, 2015). Assim, segundo a visão dos casais entrevistados, busca-se atualmente o casamento do mesmo modo que em outras épocas, sendo que os desafios inerentes a esse contrato permanecem os mesmos, com maior ou menor predominância de 
determinados aspectos em função dos comportamentos individuais que se alteram, por serem mais sujeitos à mentalidade de cada época. A maior flexibilidade nos relacionamentos, por exemplo, aponta para uma evolução. Essa flexibilidade tem sido observada a partir da maior presença da mulher no mercado de trabalho, pela revisão da divisão de tarefas no lar e pelo próprio modo como a mulher tem sido compreendida social e culturalmente (Sarti, 2010). Assim, o casamento tem se flexibilizado para abarcar essas mudanças, embora o sentido de estar junto e permanecer unidos não tenha se alterado em sua essência, de acordo com a concepção dos participantes do presente estudo. Os comportamentos sexuais contemporâneos e a abolição da exigência da virgindade feminina para legitimar o enlace conjugal, bem como o adiamento da conjugalidade e do projeto de parentalidade são fenômenos ainda recentes e que impactam a construção das novas famílias, ainda que os ideais de amor e de investimento afetivo possam ser considerados relativamente estáveis ao longo do tempo (Grizólio, Scorsolini-Comin, \& Santos, 2015).

Observa-se, atualmente, que há maior tolerância em relação à coexistência de outros modelos de relacionamento afetivo, difundidos principalmente entre os jovens, como pessoas que não desejam se casar, que adiam o casamento ou que optam por não ter filhos, ou seja, permite-se certa flexibilização em relação ao ideário do casamento sustentado nos padrões convencionais (Ribeiro et al., 2010; Saavedra \& Taveira, 2007; Scorsolini-Comin \& Santos, 2010), como ocorria, sobretudo, até o final do século XX. No entanto, apesar de se observar essa renovação no roteiro ideal do casamento com o passar dos tempos, o que constituiria, de fato, o matrimônio (amor, investimento, desejo, companheirismo) parece ter uma base estável, o que explica porque o casamento continua a despertar tanto interesse nas pessoas.

\section{O Casamento "de Hoje": Flexibilização dos Papéis de Gênero}

Se anteriormente os namoros estavam, em grande parte, associados a uma ideia de compromisso futuro, possivelmente de casamento, atualmente se compreende essa fase inicial de um relacionamento amoroso como uma possibilidade de experimentação e de maior conhecimento acerca do outro, não havendo necessariamente uma vinculação automática entre namorar e casar-se posteriormente. Embora alguns participantes analisem esse movimento com crítica, já que evidenciaria falta de compromisso, atualmente se considera o namoro como uma fase de estabilidade responsável por aproximar pessoas e gerar vínculos importantes para o desenvolvimento e bem-estar emocional. Embora os namoros na atualidade possam ser mais efêmeros, há um consenso de que esse tipo de relacionamento envolve também um tipo de compromisso e respeito mútuo, o que pode se dar de diferentes modos, a depender do par e do contrato estabelecido - por exemplo, pressupondo a manutenção da fidelidade, característica encontrada na maioria dos relacionamentos que se intitulam namoros.

Ela quer conhecer, entendeu, quer dizer que ela quer ficar, ela num tem afinidade no namoro não, ela quer é conhecer. Ela tá conhecendo, ela num tá namorando. E ai depois pega outro, vai no outro, vai no outro, outro dia é outro, entendeu, então sei lá, acho que salada de minas, meio complicado no, pra um casamento, entendeu? É dificil hoje. Não que sejam todas né, mas, tem exceção, mas hoje em dia eu vejo, pelo menos lá no meu serviço, eu vejo que ninguém tem responsabilidade com nada, entendeu. (Esposo 1, 62 anos, casado há 33 anos)

Quando se rompe a associação linear entre o namoro e o futuro compromisso com o casamento, o que já podia ser observado desde a década de 1980, opera-se também a possibilidade de que haja maior liberdade nesses relacionamentos, de modo que no namoro possa haver espaço para muitos aprendizados, inclusive no que se refere ao primeiro ato sexual, algumas vezes. É lícito pensar, desse modo, que a maior liberdade sexual e afetiva, juntamente com a aceitação social de que o namoro possa envolver a sexualidade e a atividade sexual (Bertoldo \& Barbará, 2006), acaba produzindo um estranhamento em alguns participantes, haja vista que, na época em que eles namoravam, o relacionamento antes do casamento se resumia a obter maior conhecimento da futura esposa, sem qualquer contato mais íntimo. Esse afastamento era compreendido como respeito e responsabilidade, o que, segundo alguns participantes, não ocorre atualmente.

Eu, por exemplo, sempre respeitei, até hoje ainda continuo respeitando. Num tem esse negócio de papagaiada não, sempre respeitei ela e ela me respeita também. Hoje o negócio é, já sai, já vão pra um motel, num entendo mais nada, eu num tô entendendo mais nada. O meu mundo acabou, eu tô num outro mundo. [...] Hoje é outra coisa. [...] E eu estranho. Então são coisa que, pra mim, o meu mundo acabou no ano 2000. (Esposo 5,85 anos, casado há 63 anos)

Há que se reconhecer que, atualmente, os filhos moram por mais tempo com os pais e se casam mais tarde, em um fenômeno conhecido como adolescência estendida. Nessa direção, assiste-se à priorização, muitas vezes, da carreira profissional e dos estudos, o que não significa um menor investimento no setor afetivo, mas a flexibilização no exercício da afetividade (Borges, 2013; Cavalcanti Chaves, 2010; Costa \& Mosmann, 2015; Gallagher, Féres-Carneiro, \& Henriques, 2013; Saavedra \& Taveira, 2007; Therborn, 2006).

Ao comparar o casamento experimentado pelo casal de longa duração e o observado nos dias atuais, alguns entrevistados salientaram as mudanças em relação ao papel do homem e da mulher na sociedade, sendo o casamento um lócus privilegiado para essa análise. Alguns retratam 
que, anteriormente, o homem era o único mantenedor da subsistência material da família, reforçando os estereótipos de gênero: homem provedor e mulher cuidadora (Sarti, 2010). Em algumas falas, essa clara divisão sexual de papéis, engendrada no contexto do casamento da segunda metade do século XX, seria a responsável pelas uniões bem-sucedidas, haja vista que cada um sabia qual era a sua função no contexto familiar. Ao mesmo tempo, compreendese que a mudança nos papéis prescritos é algo que extrapola o contrato matrimonial, pois incide em toda a sociedade, obrigando todos a um exercício de reconhecimento sobre as transformações que repercutem nessa estrutura (Borges, 2013; Costa, 1983; Gallagher, Féres-Carneiro, \& Henriques, 2013; Sarti, 2010; Scorsolini-Comin \& Santos, 2012; Vaitsman, 1994).

Hoje o casamento virou negócio. O casamento é um negócio hoje porque, de primeiro, casava e o marido é que ia trabalhar. O marido é que sustentava a casa. A mulher cuidava do lar, dos filhos em casa. O marido é que dava conta da obrigação dele. Hoje se casar a moça e o rapaz, se ela num trabalhar junto o marido, seja como for, não dá certo, ela tem que trabalhar. Hoje faz parte o, o trabalho da mulher com o marido, os dois trabalharem. (Esposo 3, 66 anos, casado há 42 anos)

A assunção da mulher como sujeito que não apenas transita no universo doméstico e no domínio do cuidado, mas que também pode ser independente financeiramente e buscar a realização de suas aspirações profissionais e pessoais tem sido cada vez mais absorvida e respeitada no modelo do casamento contemporâneo. Essa autonomia não se resume apenas ao contexto financeiro, mas também alcança o domínio da conjugalidade e da afetividade (Sarti, 2010). Como destacado no trecho a seguir, essa independência fez com que algumas mulheres pudessem abdicar do companheiro, mas, ao mesmo tempo, isso só seria possível se não houvesse o amor. Desse modo, a libertação do jugo masculino não a autorizaria a viver sem um lastro de dependência do marido, caso houvesse um vínculo amoroso sólido entre o par.

A mulher hoje num é muito dependente, que antigamente a mulher não podia trabalhar fora, né, era só em casa, cuidar da casa, de marido, de filho. Agora, hoje a mulher trabalha, tem o dinheiro dela, acho que ela acha que é independente, não precisa do marido, né. De certo é porque não tem amor, né, porque, se tiver, quer ficar junto, né? (Esposa 4, 86 anos, casada há 66 anos)

Nesse sentido, o homem contemporâneo tem que acompanhar essas transformações, que se tornam mais evidentes quando se analisa o papel da mulher na atual sociedade. Há que se primar por uma maior abertura, a fim de que ambos os cônjuges possam se desenvolver segundo seus projetos pessoais e suas decisões compartilhadas, sendo a conjugalidade um espaço de encontro, não de cerceamento das liberdades e desejos individuais, tampouco o principal ou único projeto de vida da mulher, como se observava anos atrás (Borges, 2013). O casamento deve se apresentar para além de sua definição sociossexual, de contenção da expressão da sexualidade, como expresso desde o início do século XX (Therborn, 2006). Em algumas falas, percebeuse que seria mais complexo para o homem compreender a assunção da mulher, haja vista que as pessoas que se casam atualmente ainda possuem resquícios de sua educação sob essa mentalidade ligada ao casamento mais tradicional e com pouca ou nenhuma flexibilidade em relação aos papéis tradicionais de gênero. Muitas vezes o exemplo do casamento dos próprios pais funciona como forte inspiração.

A maior divisão de tarefas no casal também é apontada como uma característica dos casamentos contemporâneos. Se anteriormente o cuidado com a casa e os filhos era da alçada exclusiva da mulher, com sua entrada no mercado de trabalho, acaba ocorrendo um movimento no qual o homem também passa a se responsabilizar pelo lar. Mesmo assim, a divisão de tarefas aponta para o desempenho de algumas atividades nas quais os homens não podem se engajar com muita frequência e outras nas quais é permitido que ele contribua. No que tange à mulher, ainda que trabalhe fora do lar, permanece o resquício generificado de que ela deve se devotar à casa, o que produz a chamada dupla jornada: os afazeres domésticos são assumidos no período oposto ao trabalho formal, ainda que ela possa ser ajudada, em parte, pelo esposo (Garcia \& Tassara, 2001).

Então, tem que ter uma cabeça boa pra dividir as tarefas, né, se tiver filho, ajudar ela e ela também ajudar, né, que a maioria das mulheres hoje trabalha, né. Na minha época eram poucas que trabalhavam, era mais dentro de casa, ai tinha mais tempo, né. Agora as mulheres também tudo trabalha, então, na minha opinião, isso eu até conversei, até conversei com, com, com ele [esposo], né, é dividir as tarefas. Ela sai pra trabalhar, ele sai também, "então vê se você faz isso", e então a gente conversa os dois pra poder... Então, é essa aí a opinião minha. (Esposa 1, 59 anos, casada há 33 anos).

\section{A (Im)Possibilidade do Divórcio}

A quarta e última categoria contempla o tema que mais promoveu convergências entre os relatos dos casais entrevistados. Embora haja heterogeneidade nas idades dos participantes e o tempo de união varie de 30 a 60 anos, todos foram convictos em destacar o divórcio como uma possibilidade impensável dentro de um relacionamento de longa duração. A dissolução do relacionamento conjugal é associada, na maioria das vezes, à necessidade imediata de resolver um problema de modo rápido e sem o necessário envolvimento emocional dos parceiros. Embora a popularização do divórcio tenha possibilitado avanços, os casais entrevistados reconhecem que esse dispositivo legal se tornou uma ferramenta que visa a abreviar o sofrimento 
e distanciar os cônjuges em relação ao real sentido da união conjugal. Segundo os relatos, a "facilidade" de consumar um divórcio acaba por gerar um descompromisso no par que vivencia uma situação conflituosa ou incompatibilidade de gênios, sendo uma possibilidade aventada sempre que não se vislumbrem possibilidades de conciliar as diferenças e solucionar os problemas de modo a preservar intacta a união. Tal apontamento é amparado pelo estudo de Rolim e Wendling (2013). Segundo Norgren et al. (2004), a satisfação conjugal aumenta quando são encontradas estratégias adequadas de resolução de problemas e quando predominam a coesão, proximidade e boa habilidade de comunicação no casal.

Sobre a ideia de separação dos cônjuges à época em que se casaram, alguns relatam que havia sim essa possibilidade, mas a maioria destaca que poucos eram os casos de uniões que chegavam ao fim. Normalmente, relatam que havia um preconceito muito forte em relação a quem se separava, sobretudo em relação à mulher, que era responsabilizada, na maioria dos casos, pelo fim do casamento, o que encontra ressonância em outros estudos (Coutinho \& Menandro, 2010; Nichnig, 2013). Ao se separar, a mulher corria o risco de não ser mais reconhecida como uma pessoa digna.

A possibilidade do divórcio e a assunção de diferentes arranjos familiares na contemporaneidade têm permitido que o casamento seja compreendido de uma maneira mais fluida e menos engessada pelo ideário tradicional. Os casais, embora reconheçam que os ideais do casamento ainda sejam os mesmos, relatam que as mudanças sociais, culturais, econômicas e no nível dos hábitos e costumes operou uma ressignificação acerca do casamento, a ponto deste ser considerado "raro", como fica patente no excerto de fala a seguir. Há que se considerar que a tradicional noção de casamento como possibilidade das pessoas solteiras saírem da casa dos pais, experienciarem uma sexualidade (domesticada, diga-se de passagem) e responsabilizarem-se um pelo outro até "que a morte os separe", hoje pode ser revisitada à luz de valores que acompanham as diversas transformações que impactam as instituições que oferecem suporte para a manutenção da estrutura social. A família pode ser reinventada, com espaços permeáveis ao divórcio, ao recasamento e aos questionamentos acerca das experiências, como o amor e a fidelidade, acomodando-se ao fim da ideia de indissolubilidade do laço conjugal, substituindo a antiga condição de "para sempre" por um "eterno enquanto dure". De modo análogo, o caráter aparentemente imutável dos papéis socialmente atribuídos ao homem e à mulher vem sofrendo grandes fissuras. Assim, torna-se importante compreender os valores e os modos de ser vigentes em cada período, de modo que a análise do casamento permite que se tenha uma compreensão mais abrangente e acurada das permanências e rupturas que se operam em meio às transformações que caracterizam a contemporaneidade.

Olha, eu acho o casamento hoje em dia muito raro. Assim, porque, pelos meus sobrinhos, eles brincam: "Ah, se eu casar e num der certo, eu separo”. Então é mais fácil. Então eu acredito que também às vezes a pessoa sai de um casamento que num deu certo e vai pra outro que dá certo, num é obrigado a ficar junto, né. Cada tempo é um estilo diferente, mas hoje eu acho que é bem aceitável. (Esposa 7, 71 anos, casada há 51 anos)

[...] parece que o povo num tá levando muito a sério, né. Mas igual a gente, né, na nossa época era aquela responsabilidade, aquela... Hoje parece que dá a impressão, né, que o povo num leva muito a sério. Porque, como se diz, é a conversa que a gente escuta, se casar e num der certo, separa, né. Parece que acha assim natural. Se num der certo... (Esposa 3, 61 anos, casada há 42 anos)

Contemporaneamente, é permitido não apenas que o jovem possa namorar e tenha liberdade e possibilidade de vivenciar a sua sexualidade, como também colocar à prova a durabilidade dos relacionamentos nos quais se engaja. Embora alguns entrevistados concebessem essa maior liberdade como um prejuízo ao estabelecimento dos relacionamentos estáveis, há que se considerar que existe um maior poder de escolha do parceiro, bem como a possibilidade de mudar de opinião, de rever prioridades e conhecer pessoas que se alinhem mais aos desejos e aos valores de cada um. Nesse sentido, há maior abertura para a manifestação do desejo despertado pelo ser amado, de modo a não apoiar um relacionamento em uma escolha tida como única e definitiva, que deveria ter o status de "para sempre" ou que jamais possa ser questionada. Hoje, pelo contrário, há espaço para a possibilidade de rever escolhas, repensar trajetórias e assumir o sentido de impermanência nas escolhas amorosas, com maior permeabilidade para as mudanças desenvolvimentais, sobretudo na adolescência e na transição para a vida adulta.

A aceitação do divórcio, portanto, não encerra apenas a possibilidade de romper o contrato conjugal, mas também a de permitir que os membros do casal desfeito possam refazer suas escolhas, tomar outras decisões e experimentar a afetividade em outros relacionamentos ou mesmo sozinhos, desde que sobre a pessoa não incida o olhar mortificador do preconceito, da discriminação e do cerceamento da liberdade de estabelecer vínculos afetivos e buscar expressões mais satisfatórias nos relacionamentos interpessoais (Rolim \& Wendling, 2013; Zordan \& Strey, 2011). As mudanças observadas nas falas dos participantes, embora possam sugerir um cenário de crise ou de colapso acerca da instituição casamento, podem ser compreendidas em uma perspectiva mais positiva e congruente com as transformações sociais vigentes. Assim como a sociedade e as pessoas, o casamento contemporâneo é um depositário de diversas mudanças, o que acena para a necessidade de compreender esse movimento para além dos aspectos que se modificaram, considerando também as permanências naquilo que constitui, de fato, a conjugalidade nessas duas primeiras décadas do século XXI, bem como os movimentos em torno das noções de família e relações de gênero (Borges, 2013; Nichnig, 2013), presentes de modo destacado nas falas dos participantes deste estudo. 


\section{CONSIDERAÇÕES FINAIS}

$\mathrm{Da}$ análise realizada, depreende-se que os casais longevos tiveram que reorganizar suas concepções sobre o casamento para poderem lidar com as novas possibilidades que emergem na era contemporânea. Não se trata, no entanto, de modificar as bases do próprio casamento, mas de reconhecer que as uniões atuais podem se estruturar sobre bases diferentes, menos rígidas e talvez com mais potencialidade para encontrar o outro em suas diferenças e necessidades. O respeito pela liberdade de se casar e também pela prerrogativa de se divorciar, quando o vínculo conjugal se torna insustentável, parece ser a inovação que mais repercutiu nos casais entrevistados. Esses cônjuges consideraram que essa é uma mudança de valores em relação ao que pensam que deva ser um casamento. Uma mudança que referem perceber nos outros, mas que não se aplica ao seu próprio casamento. Há que se considerar que esses casais foram escolhidos justamente por manterem relacionamentos duradouros ao longo dessas décadas de maior transformação na instituição casamento. São cônjuges que puderam observar as mudanças a partir de um prisma específico, o do próprio casamento, considerado um compromisso, uma responsabilidade e um valor indissolúvel na maioria das histórias reconstituídas. Embora essa seja uma visão que possa ser considerada essencialmente conservadora e pouco flexível, no sentido de incorporar as novas concepções que regulam a relação conjugal, deve-se destacar que os entrevistados sentiram que foram contestados em seus valores ao longo da educação dos filhos e do contato com as novas gerações, como os netos, que já puderam experienciar uma concepção mais ampliada acerca do casamento.

Muito do que os casais colaboradores desta pesquisa relataram tem como ponto de partida narrativas da própria família, de filhos, sobrinhos e netos, de modo que as transformações mostram-se cada vez mais próximas e familiares, o que poderia convidá-los também para revisitar o próprio casamento. Nesse sentido, o convite do presente estudo foi que pudessem olhar para a própria conjugalidade ao longo dos anos, sendo o relato do que compreendem por casamento um recorte oportuno e que lhes tem revelado um sentido de permanência em meio a um cenário de emergência de novos modelos, que têm se mostrado permeáveis a questionamentos acerca das estruturas mais rígidas e tradicionais que delineiam a família e também os papéis de gênero.

Há que se recuperar a noção de que a conjugalidade é uma dimensão em permanente mudança, o que incorpora não apenas a reformulação das experiências íntimas e pessoais dos parceiros, mas também os aspectos sociais mais amplos que, por vezes, lançam questionamentos a uma estrutura que até então parecia ser sólida e avessa a transformações. Nesse sentido, abre-se a necessidade de maior discussão, nos estudos vindouros, sobre os papéis de gênero assumidos, negados e incorporados por esses casais ao longo do tempo, o que parece balizar importantes movimentos no sentido da própria compreensão do que vem a ser um relacionamento conjugal. Há que se compreender, ainda, se tais papéis e suas transformações ao longo do tempo estariam associados à própria manutenção do casamento nos casais longevos.

Uma limitação do presente estudo foi a composição dos participantes, recrutados em apenas uma cidade e com aspectos sociais e culturais que demarcam possibilidades mais rígidas em relação ao casamento e à construção da família. Para os próximos estudos acerca dessa temática, recomendase uma maior diversificação da amostra, contemplando distintos cenários culturais, o que pode promover o acesso a diferentes modos de manejo da conjugalidade, das questões de gênero e das próprias considerações acerca de família, parentalidade e conjugalidade. Por fim, acreditase que a presente investigação possa contribuir com os estudos nacionais sobre a conjugalidade de longa duração, ampliando o conhecimento produzido e permitindo uma compreensão mais dinâmica acerca desses relacionamentos.

\section{AGRADECIMENTOS}

Este estudo recebeu o apoio do Conselho Nacional de Desenvolvimento Científico e Tecnológico (CNPq): Bolsa de Pós-Doutorado Junior Processo 501391/2013-4 para o primeiro autor (F.S-C), e bolsa de iniciação científica para a segunda autora (J.D.A-S). E da Fundação de Amparo à Pesquisa do Estado de Minas Gerais (FAPEMIG), por meio de Edital de Demanda Universal. A estas agências, nosso agradecimento.

\section{REFERÊNCIAS}

Ariès, P. (1981). História social da criança e da família (2a ed.). Rio de Janeiro: LTC.

Ahmadi, K., Rezazade, M., Saadat, H., Kimiaei, S. A., \& Zade, N. H. (2015). Contribution of marital conflict to marital quality in short and long-term marriages: An actor-partner interdependence model. Journal of Education and Health Promotion, 4, 42.

Bachand, L. L., \& Caron, S. L. (2001). Ties that bind: A qualitative study of happy long-term marriages. Contemporary Family Therapy, 23(1), 105-121. 
Bertoldo, R. B., \& Barbará, A. (2006). Representação social do namoro: A intimidade na visão dos jovens. Psico-USF, 11(2), 229-237.

Borges, C. C. (2013). Mudanças nas trajetórias de vida e identidades de mulheres na contemporaneidade. Psicologia em Estudo, 18(1), 71-81.

Campos, S. O., Scorsolini-Comin, F., \& Santos, M. A. (2017). Transformações da conjugalidade em casamentos de longa duração. Psicologia Clínica, 29(1), 69-89.

Cavalcanti Chaves, J. (2010). As percepções de jovens sobre os relacionamentos amorosos na atualidade. Psicologia em Revista, 16(1), 28-46.

Costa, J. F. (1983). Ordem médica e norma familiar. Rio de Janeiro: Graal.

Costa, C. B., \& Mosmann, C. P. (2015). Relacionamentos conjugais na atualidade: Percepções de indivíduos em casamentos de longa duração. Revista da SPAGESP, 16(2), 16-31.

Costa, C. B., Mosmann, C., \& Falcke, D. (2015). Marital conflicts in long-term marriages: Motives and feelings. Psicologia em Estudo, 20(3) 411-423.

Coutinho, S. M. S., \& Menandro, P. R. M. (2010). Relações conjugais e familiares na perspectiva de mulheres de duas gerações: "Que seja terno enquanto dure". Psicologia Clínica, 22(2), 83-106.

Del Priore, M. (2006). História do amor no Brasil (2a ed.). São Paulo: Contexto.

Féres-Carneiro, T., \& Diniz Neto, O. (2010). Construção e dissolução da conjugalidade: Padrões relacionais. Paidéia, 20(46), 269-278.

Gallagher, I. M., Féres-Carneiro, T., \& Henriques, C. R. (2013). Planos para o futuro: Percepções de filhos adultos coabitantes com os pais. Revista da SPAGESP, 14(2), 4-18.

Garcia, M. L. T., \& Tassara, E. T. O. (2001). Estratégias de enfrentamento do cotidiano conjugal. Psicologia: Reflexão e Crítica, 14(3), 635-642.

Grizólio, T. C., Scorsolini-Comin, F., \& Santos, M. A. (2015). The perception of parenting couples engaged in long-term marriages. Psicologia em Estudo, 20(4), 657-667.

Instituto Brasileiro de Geografia e Estatística. (2015). Estatísticas do Registro Civil de 2014. Rio de Janeiro.

Jablonski, B. (1998). Até que a vida nos separe: A crise do casamento contemporâneo. Rio de Janeiro: Agir.

Landis, M., Peter-Wight, M., Martin, M., \& Bodenmann, G. (2013). Dyadic coping and marital satisfaction of older spouses in long-term marriage. GeroPsych, 26(1), 39-47.

Margelisch, K., Schneewind, K. A., Violette, J., \& Perrig-Chiello, P. (2015). Marital stability, satisfaction and well-being in old age: Variability and continuity in long-term continuously married older persons. Aging \& Mental Health. doi: 10.1080/13607863.2015.1102197

Nichnig, C. R. (2013). Mulher, mulheres, mulherio: Discurso, resistência e reinvidicações por direitos. Rio de Janeiro: Multifoco.

Norgren, M. B. P., Souza, R. M., Kaslow, F, Hammerschmidt, H., \& Sharlin, S. A. (2004). Satisfação conjugal em casamentos de longa duração: Uma construção possível. Estudos de Psicologia (Natal), 9(3), 575-584.

Perlin, G. D. B., \& Diniz, G. R. S. (2005). Casais que trabalham e são felizes: Mito ou realidade? Psicologia Clínica, 17(2), 15-29.
Ribeiro, R. M., Sabóia, A. L., Branco, H. C., \& Bregman, S. (2010). Estrutura familiar, trabalho e renda. In S. M. Kaloustian. (Org.), Família brasileira, a base de tudo (pp. 111-130). São Paulo: Cortez/Brasília: Unicef.

Rolim, K. I., \& Wendling, M. I. (2013). A história de nós dois: Reflexões acerca da formação e dissolução da conjugalidade. Psicologia Clínica, 25(2), 165-180.

Rosowsky, E., King, K. D., Coolidge, F. L. Rhoades, C. S., \& Segal, D. L. (2012). Marital satisfaction and personality traits in longterm marriages: An exploratory study. Clinical Gerontologist, $35,77-87$.

Saavedra, L., \& Taveira, M. C. (2007). Discursos de adolescentes sobre a vida profissional e familiar: Entre o sonho e a realidade. Educação \& Sociedade, 28(101), 1375-1391.

Sandberg, J. G., Miller, R. B., Harper, J. M., Robila, M., \& Davey, A. (2009). The impact of marital conflict on health and health care utilization in older couples. Journal of Health Psychology, 14(1), 9-17.

Sarti, C. A. (2010). A família como espelho: Um estudo sobre a moral dos pobres ( $6^{\mathrm{a}}$ ed.). São Paulo: Cortez.

Scorsolini-Comin, F. (2014). Aconselhamento psicológico com casais: Interlocuções entre Psicologia Positiva e abordagem centrada na pessoa. Contextos Clínicos, 7(2), 192-206.

Scorsolini-Comin, F., \& Santos, M. A. (2010). Sustentabilidade dos afetos: Notas sobre a conjugalidade como dimensão de análise da família na contemporaneidade. Psychologica, 53(1), 259-274.

Scorsolini-Comin, F., \& Santos, M. A. (2012). Correlations between subjective well-being, dyadic adjustment and marital satisfaction in Brazilian married people. The Spanish Journal of Psychology, 15(1), 166-176.

Sharlin, A. S, Kaslow, F., \& Hammerschmidt, H, (2000). Together through thick and thin: A multinational picture of long-term marriages. Nova York: The Haworth Clinical Practice Press.

Silva, L. A., Scorsolini-Comin, F., \& Santos, M. A. (2018). Motivations for the maintenance of marriage. Psicologia em Estudo, 23, e41155.

Therborn, G. (2006). Sexo e poder: A família no mundo (1900-2000) (E. D. Bilac, Trad.). Rio de Janeiro: Contexto.

Triviños, A. N. S. (1987). Introdução à pesquisa em ciências sociais: A pesquisa qualitativa em educação. São Paulo: Atlas.

Vaitsman, J. (1994). Flexiveis e plurais: Identidade, casamento e família em circunstâncias pós-modernas. Rio de Janeiro: Rocco.

Zordan, E. P., \& Strey, M. N. (2011). Separação conjugal: Aspectos implicados nessa decisão, reverberação e projetos futuros. Pensando Famílias, 15(2), 71-88. 